\title{
Comparison of time-matched aerobic, resistance or combined exercise training in women living with obesity: a protocol for a pilot randomised controlled trial-the EXOFFIT (Exercise for Obesity in Females to increase Fitness) study
}

\author{
Mary E. Davis ${ }^{1 *} \mathbb{0}$, Catherine Blake ${ }^{1}$, Caitriona Cunningham¹, Brian P. Carson² and Gráinne O'Donoghue ${ }^{1}$
}

\begin{abstract}
Introduction: Obesity in women has more than doubled in the past thirty years. Increasing research suggests that increased cardiorespiratory fitness (CRF) can largely attenuate the negative health risks associated with obesity. Though previous literature suggests that combined training may be the most effective for improving CRF in adults with obesity, there is minimal research investigating the efficacy of combined and resistance programmes in women with obesity. This article outlines a protocol for a parallel pilot study which aims to evaluate the feasibility and efficacy of three exercise modalities in women with obesity for increasing CRF and strength and improving body composition and other health outcomes (i.e. quality of life).
\end{abstract}

Methods and analysis: Sixty women (aged 18-50) with obesity (body mass index [BMI] $\geq 30$ and/or waist circumference $\geq 88 \mathrm{~cm}$ ) who are physically inactive, have no unstable health conditions and are safe to exercise will be recruited from September 2021 to December 2022. The main outcome will be feasibility and acceptability of the intervention and procedures. Trial feasibility outcomes will be evaluated to determine if a definitive trial should be undertaken. Trial acceptability will be explored through follow-up qualitative interviews with participants. Secondary outcomes will include CRF (predicted $\mathrm{VO}_{2}$ max), anthropometrics (i.e. BMI), strength (5RM bench press, leg dynamometry, grip strength) and other health outcomes (i.e., pain). Participants will be block randomised into one of four trial arms (aerobic exercise, resistance training and combined training groups, non-active control group) and measurements will be completed pre- and post-intervention. The exercise groups will receive an individualised supervised exercise programme for $3 \times$ sessions/week for 12 weeks. The change in mean values before and after intervention will be calculated for primary and secondary outcomes. ANOVA and t-tests will be applied to evaluate within-group and between-group differences. If sufficient participants are recruited, the data will be analysed using ANCOVA with the age and BMl as covariates.

*Correspondence: mary.davis@ucdconnect.ie

1 Department: School of Public Health, Physiotherapy and Sports Science,

University College Dublin, Dublin 4, Ireland D04 V1W8

Full list of author information is available at the end of the article

(c) The Author(s) 2022. Open Access This article is licensed under a Creative Commons Attribution 4.0 International License, which permits use, sharing, adaptation, distribution and reproduction in any medium or format, as long as you give appropriate credit to the original author(s) and the source, provide a link to the Creative Commons licence, and indicate if changes were made. The images or other third party material in this article are included in the article's Creative Commons licence, unless indicated otherwise in a credit line to the material. If material is not included in the article's Creative Commons licence and your intended use is not permitted by statutory regulation or exceeds the permitted use, you will need to obtain permission directly from the copyright holder. To view a copy of this licence, visit http://creativecommons.org/licenses/by/4.0/. The Creative Commons Public Domain Dedication waiver (http://creativeco mmons.org/publicdomain/zero/1.0/) applies to the data made available in this article, unless otherwise stated in a credit line to the data. 
Discussion: This pilot will provide data on the feasibility and acceptability of trial procedures and of the programmes' three progressive time-matched exercise interventions (aerobic, resistance and combined) for women living with obesity, which will help inform future research and the potential development of a full-scale randomised clinical trial.

Trial registration: ISRCTN, ISRCTN13517067. Registered 16 November 2021-retrospectively registered.

Keywords: Obesity, Women, Exercise, Fitness, Training

\section{Background}

Despite decades of awareness of the obesity challenge, this chronic disease continues to prevail as one of the world's leading causes of morbidity and mortality $[1,2]$. Women, in particular, appear more susceptible to obesity, with the prevalence of female obesity having more than doubled in the past 30 years and the prevalence of morbid obesity in women more than twice that recorded in men [3]. Evidence suggests that among adults, young women of childbearing age (18-44 years) are the most at risk of developing obesity $[4,5]$, with this cohort demonstrating the highest rate of weight gain [6-10]. Furthermore, the adverse effects associated with obesity appear to be greater in women, with the risks of developing cancer and cardiovascular and metabolic disorders significantly higher than observed in men [11-15]. Mounting evidence highlights the strong association between excessive weight gained during early childbearing years and longer-term adverse health outcomes [4, 16-18].

Encouragingly, increasing literature indicates that improvements in cardiorespiratory fitness (CRF), attainable through exercise, can largely attenuate the healthrelated risk factors, regardless of obesity severity [19-23]. Noteworthy, however, is that women, particularly young women, are significantly less active than their male counterparts [19, 20, 24, 25]. Globally an estimated 1 in 3 women do not meet generic exercise guidelines (150 $\mathrm{min} /$ week of moderate-intensity aerobic exercise, $\times 2$ days/week of moderate-high intensity resistance training), with some country-specific statistics indicating that closer to 1 in 2 women aged 18-54 not meeting these recommendations [26-30]. This physical inactivity has been shown to strongly correlate with excessive weight gain in the short term and the development of cardiovascular risk factors over the longer term in this cohort [5, 31-33]. Alongside physiological differences between men and women (i.e. body size, muscle and fat mass, cardiac output etc.) [33-36], physical inactivity as a behaviour, has been identified as a stronger determinant of CRF in women [37], with the literature reporting an estimated average difference in CRF up to $20 \%$ between the sexes (in both active and inactive adults) [37-39].

To date, it is unclear how this difference in CRF translates to sex-specific responses to exercise training in the context of obesity. Evidence based on normal weight, healthy adults, suggests that males demonstrate greater increases in both absolute and relative maximal oxygen uptake $\left(\mathrm{VO}_{2} \max \right)$ in response to training, and highlights a more blunted adaption to training in females $[40,41]$. Most literature investigating the effcacy of exercise in women with obesity has primarily focused upon the prescription of interventions based upon generic physical activity guidelines, where moderate-intensity aerobic exercise is advocated. Although most of the studies focus on weight loss, the few that include CRF as an outcome measure, have observed small to moderate improvements in CRF [42-45]. Previous literature, including a recent network meta-analysis, indicate that combined (aerobic and resistance) interventions (particularly high intensity) are the most promising for improving CRF and body composition in adults living with obesity [46, 47]. However, most of the available studies which investigated resistance training or combined training were in men. Additionally, a recent systematic review and meta-analysis (conducted by this protocol's author [M.E.D] and colleagues) which focused solely on women with obesity, further highlighted both the paucity of well-designed exercise intervention studies focused on young women with obesity and the lack of research investigating CRF and other measures of health such as quality of life, pain and mood.

\section{Aims and objectives}

Therefore, the primary aim is to evaluate the feasibility and acceptability of prescribed time-matched aerobic, resistance and combined interventions (targeting changes in cardiorespiratory fitness) in women with obesity and to inform whether a future definitive trial could or should be undertaken. We will assess recruitment challenges; retention rates, attendance rates and adherence of participants to prescribed programme, incidence of adverse events and participant's experience of the intervention and the acceptability of trial procedures and the programmes. We will also collect data from which a power calculation can be based to determine the number of participants needed per group in order to achieve significance in a potential follow-up randomised controlled trial (RCT). 
The secondary objectives are to determine the mean difference between groups (three exercise groups and a non-exercise control group) at 12 weeks in:

(i) $\mathrm{CRF}$ (predicted $\mathrm{VO}_{2} \max$ )

(ii) anthropometric outcomes (Body mass index (BMI), percentage body fat (\%BF), lean mass (LM), fat mass (FM), waist-hip ratio (WHR) and waist circumference (WC)

(iii) strength (five repetition maximum [5RM] bench press, leg dynamometry, grip strength)

(iv) self-reported quality of life, physical activity, sedentary time, sleep, mood and pain

\section{Hypotheses tested}

Primary null hypothesis: Post intervention, there is no difference in outcomes (CRF, strength, body composition, self-reported) between participants randomised to the exercise interventions and the control.

Secondary null hypothesis: Post intervention, there is no difference in outcomes (CRF, strength, body composition) between participants randomised to the aerobic exercise, resistance training and combined training groups.

\section{Methods}

\section{Quantitative study}

Trial design

This four-arm parallel pilot study has been approved by University College Dublin (UCD) Human Research Ethics Committee (LS-21-59-Davis-ODonoghue) and will be reported in line with the Consolidated Standards of Reporting Trials (CONSORT) guidelines extension for randomised pilot and feasibility trials [48] and the Standard Protocol Items: Recommendations for Interventional Trials (SPIRIT) [49]. Following initial screening, the participants will be randomised with an allocation ratio of 1:1:1:1 into one of the three timematched exercise modes or control (Figs. 1 and 2).

1) Aerobic: progress to $150 \mathrm{~min} /$ week of continuous aerobic exercise at $75-80 \%$ HRR

2) Resistance training: progress to $150 \mathrm{~min} /$ week of 3-6 $\times 12$ reps of resistance exercise at $75-80 \% 1-\mathrm{RM}$

3) Combined training: progress to a $50: 50$ split of combined aerobic (75-80\% HRR) and resistance (3-6 $\times$ 12 reps, 3 exercises at $75-80 \%$ 1RM) training for 150 $\mathrm{min} /$ week

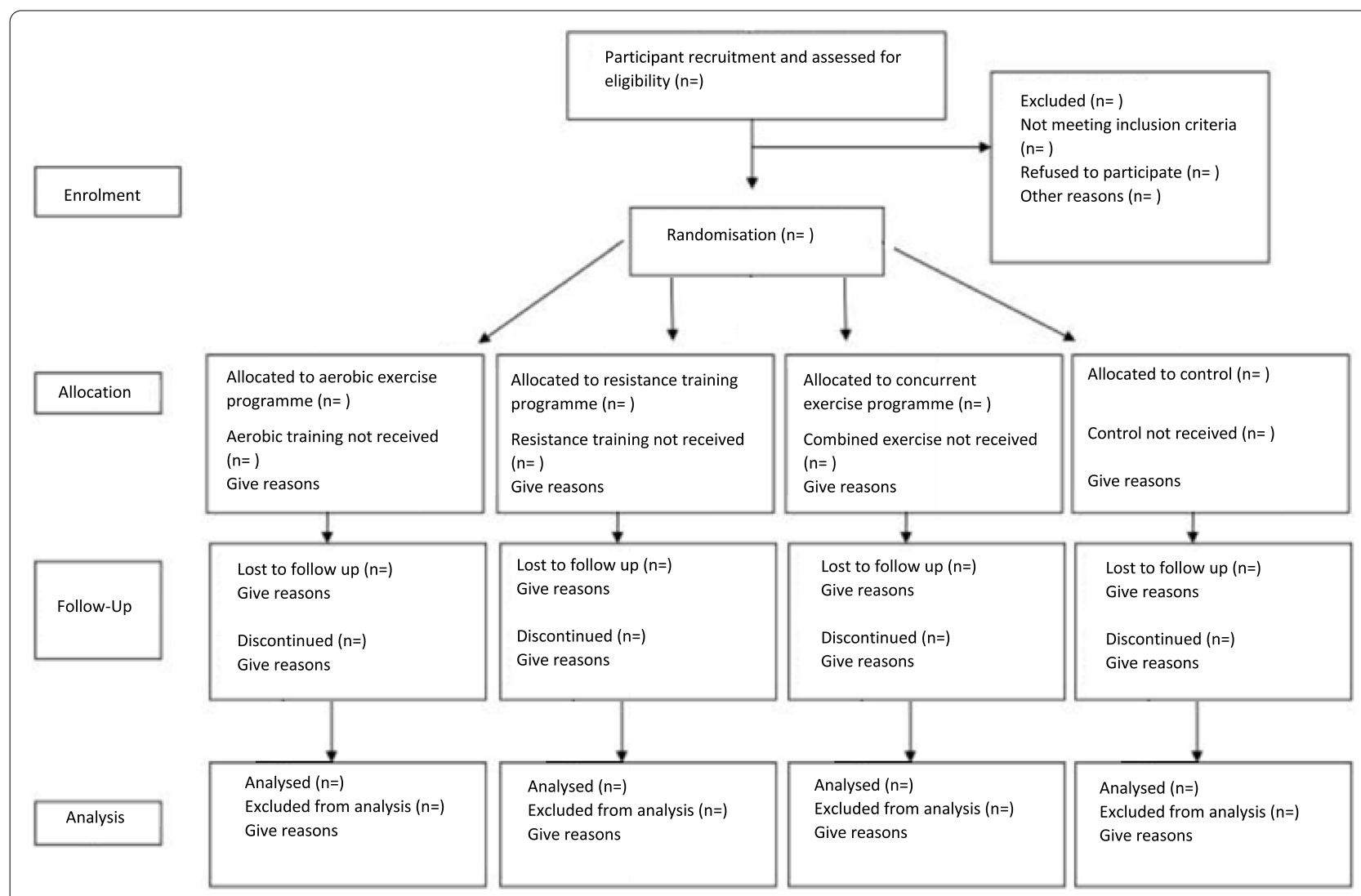

Fig. 1 Participant flow through the pilot (based on CONSORT statement) 


\begin{tabular}{|c|c|c|c|c|c|}
\hline \multirow[b]{3}{*}{ TIMEPOINT** } & \multicolumn{5}{|c|}{ Study Period } \\
\hline & \multirow{2}{*}{$\begin{array}{c}\text { Enrolment } \\
\text { Week } 0\end{array}$} & \multirow{2}{*}{$\begin{array}{c}\text { Allocation } \\
\text { Week } 0\end{array}$} & \multicolumn{2}{|c|}{ Post Allocation } & \multirow{2}{*}{$\begin{array}{r}\text { Close Out } \\
\text { Weeks 13-1 }\end{array}$} \\
\hline & & & Week 1 & Week 12 & \\
\hline \multicolumn{6}{|l|}{ ENROLMENT: } \\
\hline \multirow{4}{*}{$\begin{array}{r}\text { Sociodemographic Data } \\
\text { Random Allocation }\end{array}$} & $\mathrm{X}$ & & & & \\
\hline & $\mathrm{X}$ & & & & \\
\hline & $\mathrm{X}$ & & & & \\
\hline & & $\mathrm{X}$ & & & \\
\hline \multicolumn{6}{|l|}{ INTERVENTIONS: } \\
\hline \multicolumn{6}{|l|}{ Aerobic Exercise } \\
\hline \multicolumn{6}{|l|}{ Resistance Exercise } \\
\hline \multicolumn{6}{|l|}{ Combined exercise } \\
\hline \multicolumn{6}{|l|}{ Control Group } \\
\hline \multicolumn{6}{|l|}{ ASSESSMENTS } \\
\hline $\begin{array}{r}\text { Cardiorespiratory Fitness } \\
\text { (VO2 Max) }\end{array}$ & $x$ & & & & $x$ \\
\hline \multirow[b]{2}{*}{$\begin{array}{r}\text { Body Composition (BW, } \\
\% B F, \text { etc.) }\end{array}$} & $\mathrm{X}$ & & & & $\mathrm{X}$ \\
\hline & $x$ & & & & $x$ \\
\hline Pain (BFI) & $\mathrm{X}$ & & & & $\mathrm{X}$ \\
\hline Quality of Life (EQ-5D-5L) & $\mathrm{X}$ & & & & $\mathrm{x}$ \\
\hline Sleep (PSQI) & $\mathrm{X}$ & & & & $\mathrm{X}$ \\
\hline Physical Activity (IPAQ) & $\mathrm{X}$ & & & & $\mathrm{X}$ \\
\hline Mood (PHQ9) & $\bar{X}$ & & & & $\mathrm{x}$ \\
\hline \multirow{2}{*}{$\begin{array}{r}\text { Exit Questionnaire } \\
\text { Qualitative experience of } \\
\text { trial (interview) }\end{array}$} & & & & & $\mathrm{X}$ \\
\hline & & & & & $x$ \\
\hline \multicolumn{6}{|l|}{ Participant Attendance } \\
\hline $\begin{array}{r}\text { Exercise Compliance } \\
\text { (reps/sets/etc) }\end{array}$ & & & & & \\
\hline
\end{tabular}

Fig. 2 Schedule of enrolment, interventions, and assessments (based on SPIRIT protocol)

4) Control: non-exercise group (participants to maintain baseline physical activity levels)

\section{Study setting}

The study will be conducted in University College Dublin (UCD) in Dublin, Ireland from September 2021 to December 2022. Baseline/follow-up assessments and all exercise intervention arms will take place in UCD Institute for Sport and Health (ISH).

\section{Participants}

Participants will be recruited using a flyer which will be distributed in UCD internal networks, on social media platforms and in local areas (clinics, health centres, pharmacies) and shared with the chairperson of the Irish Coalition for People Living with Obesity (ICPO) with its members. Interested participants will be encouraged to contact the trial coordinator (M.E.D) who will complete eligibility screening over the telephone using the criteria detailed in Table 1 to evaluate a participant's eligibility and individual safety for starting an exercise programme using the Physical Activity Readiness Questionnaire for 
Table 1 Eligibility criteria for inclusion in trial

\begin{tabular}{ll}
\hline Criterion & Characteristics of eligible participants \\
\hline 1 & Female aged $18-50$ years at time of consent \\
2 & Have a Body Mass Index $(\mathrm{BMI}) \geq 30 \mathrm{~kg} \mathrm{~m}^{-2}$ and /or a waist circumference $>88 \mathrm{~cm}$ \\
3 & Are currently physically inactive (exercising less than $150 \mathrm{~min} /$ week) \\
4 & Have not undergone weight loss surgery or another surgery in the past 3 months \\
5 & Not pregnant (or within 6 months post-pregnancy) or lactating \\
6 & Do not have a significant mental illness or cognitive deficits \\
7 & Are not participating in another trial (exercise-based or targeting weight-loss) at time of consent \\
8 & Are not contraindicated or no clinician (i.e. GP) has advised them against exercising (i.e. chest \\
9 & pain during activity or at rest, severe hypertension etc.) \\
\hline
\end{tabular}

Everyone (PAR-Q+). If screened as eligible, potential participants will receive the study information sheet and consent form by email or by post (preferred method). All consenting participants will be invited to ISH for baseline assessment a minimum of seven days later (cooling off period) (Fig. 2).

\section{Baseline assessment}

On arrival at UCD ISH, the trial coordinator will meet potential participants and provide an overview of the study, an introduction to the tests that will be performed, the equipment that will be used and the purpose of each test. Participants will have the opportunity to ask any questions about the study at this time. Signed consent forms will be collected from willing participants. No study procedures will commence until written consent is obtained.

Sociodemographic and related health information of participants will be collected, including education employment status, medical and exercise participation history. Participants resting blood pressure and heart rate will be measured three times and an average calculated. Blood pressure will be measured on the upper arm using a wireless blood pressure monitor (make: Omron; model: Evolv) prior to the test. For participants where the bicep cuff is undersized, a wrist monitor will be used (make: Omron; model: R57 Intelli IT). In order to be eligible to continue to exercise testing, participants must have a resting blood pressure $\leq 160 / 100$ (grade 2 hypertension) [50]. Once there are no contraindications to exercise testing recorded [51], objective measures of anthropometry, strength and CRF will follow.

Anthropometry The following anthropometric/body composition variables will be collected (body mass index $[\mathrm{BMI}]$, body weight $[\mathrm{BW}]$, body fat percentage $[\% \mathrm{BF}]$, waist circumference [WC], lean mass [LM], fat-free mass [FFM], waist-hip ratio [WHR], height). All outcomes will be measured using standard procedure with participants dressed in light, close-fitted clothes and with bare feet. Height, WC and BW will be measured to the nearest $0.1 \mathrm{~cm}$ and $0.1 \mathrm{~kg}$ respectively using a calibrated scales, stadiometer and tape measure respectively. Waist circumference will be recorded midway between the top of the pelvic bone and the bottom margin of the last rib using a tape measure [52]. Whole body composition will be measured using a bioelectrical impedance body composition analyser (seca mBCA 515).

Muscular strength In order to measure strength, a 5RM bench press, leg dynamometry and grip strength will be used. To measure repetition maximum for bench press, participants will be instructed on proper form for this exercise and guided through progressive lifts where the weight will be increased in increments of $1.25-2.5 \mathrm{~kg}$ as needed until the participant reaches a weight at which they cannot perform all 5 reps of the movement maintaining good form. Fifty seconds of rest will be provided between attempts.

Leg strength will be measured using a back-leg strength dynamometer (Takei Back-D TKK 5402, Takei Scientific Instruments, Japan). Participants will be instructed to stand on the base of the machine, with feet shoulder width apart and their back bent slightly forward at the hips. The length of the chain will be adjusted so that the base of the bar rests superior to the anterior pole of the patella. Looking forward with a straight back, participants will be instructed to pull on the chain as hard as they can for $3 \mathrm{~s}$ in one fluid movement. Participants will be instructed to perform this test three times, with a rest of $50 \mathrm{~s}$ after each attempt. The maximum weight $(\mathrm{kg})$ of all three attempts will be recorded. Grip strength will be measured using a hand-held dynamometer (Jamar Hydraulic Hand Dynamometer, Performance Health Supply, USA). To perform this measure, participants will 
be placed in sitting and the dominant arm supported on a side table and positioned with shoulder adducted, neutrally rotated, elbow flexed at $90^{\circ}$, forearm in neutral position and wrist between $0-30^{\circ}$ dorsiflexion and $0-15^{\circ}$ ulnar deviation [53]. The dynamometer handle will be set to the second handle position from the inside. Participants will be instructed to squeeze the handle for $3 \mathrm{~s}$ and will perform the test three times, with a rest of $50 \mathrm{~s}$ between attempts. The maximum weight $(\mathrm{kg})$ of all three attempts will be recorded.

Cardiorespiratory fitness Given this study will recruit some high-risk participants (obesity class I: BMI 30-30.9 $\mathrm{kg} / \mathrm{m}^{2}$, obesity class II: BMI $35-39.9 \mathrm{~kg} / \mathrm{m}^{2}$ and obesity class III: BMI $\geq 40 \mathrm{~kg} / \mathrm{m}^{2}$ ) [51, 54] and in order to protect participant safety, a submaximal graded walking treadmill (make: h/p/cosmos; model: quasar) test will be conducted and used to estimate $\mathrm{VO}_{2}$ max. Guided by the Balke-Ware protocol for females [55], participants will warm-up for $4 \mathrm{~min}$ starting at a speed of $3.2 \mathrm{~km} / \mathrm{hr}$ and an incline of $0 \%$ and progressing to $3.8 \mathrm{~km} / \mathrm{h}$ by the end of the warmup, in line with the speed recommended for adults with obesity in the modified Balke protocol [56] With the speed remaining consistent, the gradient will then be increased by $2.5 \%$ every 3 min up until a gradient of $25 \%$. If the participant has not achieved any of the criteria for test termination at this stage, the speed of the treadmill will then be increased by $0.3 \mathrm{~km} / \mathrm{h}$ every 3 min until they do so. The test will be deemed complete and terminated once the participant reaches $85 \%$ of their age-predicted $\mathrm{HR}_{\max }$. Alternatively, the test will be terminated before the participant reaches $85 \%$ of agepredicted $\mathrm{HR}_{\max }$ if (i) they report a rating of perceived exertion (RPE) $\geq 18$ or (ii) reach volitional exhaustion. An RPE cut-off was included as a potential reason for test termination given that RPE $\geq 17-19$ has both been utilised as a criterion for achieving $\mathrm{VO}_{2} \max$ [57] and previously as a criterion for the termination of a submaximal Balke treadmill protocol in a clinical population $[58,59]$.
Furthermore, research indicates that RPE $>17$ reasonably correlates with $\mathrm{VO}_{2}$ max and can be used to predict $\mathrm{VO}_{2}$ max with acceptable accuracy [60].

$\mathrm{VO}_{2}$ max will be estimated using the Fitness Registry and the Importance of Exercise National Database (FRIEND) equation $\left(\mathrm{VO}_{2} \max =\right.$ speed $\times(0.17+$ fractional grade $\times 0.79)+3.5)[61]$. Gas exchange including $\mathrm{O} 2$ and $\mathrm{CO} 2$ concentrations, and respiratory exchange ratio (RER) will be measured using a gas analysis system (make: COSMED; make: Quark CPET, Rome, Italy). Heart rate will be measured every minute throughout the test by a heart rate monitor (make: Polar; model: Wind with WearLink chest belt). As CRF is being measured using a sub-maximal protocol, electrocardiograms will not be used during testing. Rating of perceived exertion (RPE) will be measured using the Borg RPE scale every minute of the test [62].

Subjective self-report questionnaires All participants will be issued a combined set of valid and reliable selfreported outcome questionnaires detailed in Table 2 . These will take approximately $30 \mathrm{~min}$ to complete. The participant will be given the option to complete these surveys online or in paper format. Participants who wish to complete the questionnaires online will be sent an email with the link and the option to complete them either in advance or following their appointment in ISH. The self-reported measures are in line with the core outcome set for weight management interventions in adults with obesity $[63,64]$. In addition, pain was included as an outcome given the strong association between chronic pain and obesity and the potential impact of pain on exercise adherence $[65,66]$.

\section{Randomisation}

A member of the research team, with no involvement in the baseline/follow-up assessments or delivery of the

Table 2 Primary and secondary outcome measures

\begin{tabular}{|c|c|}
\hline Outcomes & Measure(s) \\
\hline Anthropometrics & $\begin{array}{l}\text { BMI, body weight, \% body fat, waist circumference, fat-free } \\
\text { mass, lean mass, waist hip ratio, height }\end{array}$ \\
\hline Cardiorespiratory Fitness & Predicted $\mathrm{VO}_{2}$ max \\
\hline Muscle strength & 5RM bench press, leg dynamometry, grip strength \\
\hline Pain & Brief Pain Inventory (Short form) \\
\hline Health-related quality of life & EuroQol-5D-5L (EQ-5D-5L) questionnaire \\
\hline Mood & Patient Health Questionnaire-9 (PHQ-9) \\
\hline Self-reported physical activity \& sedentary time & International Physical Activity Questionnaire (IPAQ) (Short Form) \\
\hline Sleep & Pittsburgh Sleep Quality Index \\
\hline
\end{tabular}


interventions will independently assign all consenting participants a unique number using a random number table. Another independent investigator will utilise a computer-generated random allocation sequence to allocate numbered participants to each of the trial arms. Participants will be block randomised in blocks of four. The trial coordinator (M.E.D) will then contact this independent investigator to obtain each participant's random group allocation.

\section{Interventions}

All exercise interventions are 12-week programmes, comprised of $3 \times 50$-min sessions per week. All sessions will be supervised by trained exercise monitors/instructors (monitor: participant ratio 1:1) and will start and end with warm-up and cool-down exercises (i.e. low-intensity cycling or cross trainer, general whole body movements and stretches).

Aerobic This intervention consists of $3 \times 50-\mathrm{min}$ sessions per week of progressive continuous aerobic exercise, completed on a cross-trainer or stationary bike or combination of both. Over the course of weeks 1 to 6 , session length will gradually increase (in 5-min blocks) until participants can perform $3 \times 50$-min sessions in week 7 . The programme will progressively increase in intensity from weeks 1 to 12 (Table 3), starting at an intensity of $40-50 \%$ HRR (weeks 1-2) and finishing at an intensity of $75-80 \%$ HRR (weeks 11-12). Participants will wear heart rate monitors and use the RPE scale to monitor intensity levels (make: Garmin; model: Forerunner 45).

Resistance This intervention consists of $3 \times 50$-min sessions per week of progressive resistance exercises. During weeks $1-6$, session length will gradually progress until participants can perform $3 \times 50$-min sessions in week 7 (Table 3). The resistance programme contains eighteen exercises, with an equal amount of upper limb (shoulder press, bench press, bicep curl, raise, triceps exercises, bent-over row) core (seated and standing twists, hip bridge, 4-point kneel, overhead ball slam, push-ups) and

Table 3 Progression plan from week 1 to week 12 for all exercise groups

\begin{tabular}{|c|c|c|c|c|c|c|}
\hline \multicolumn{7}{|c|}{ Summary description of exercise interventions [frequency, intensity, time and type (F.I.T.T.)] } \\
\hline Trial arm & Weeks 1-2 & Weeks 3-4 & Weeks 5-6 & Weeks 7-8 & Weeks 9-10 & Weeks 11-12 \\
\hline Aerobic & $\begin{array}{l}3 \text { sessions/week } \\
\text { Low Intensity } \\
(40-50 \% \text { HRR) } \\
\text { Continuous aerobic } \\
\text { exercise } \\
20-30 \text { min }^{b}\end{array}$ & $\begin{array}{l}3 \text { sessions/week } \\
\text { Low-moderate } \\
\text { intensity (50-55\% } \\
\text { HRR) } \\
\text { Continuous aerobic } \\
\text { exercise } \\
30-40 \text { min }^{b}\end{array}$ & $\begin{array}{l}3 \text { sessions/week } \\
\text { Low-moderate } \\
\text { Intensity (55-60\% } \\
\text { HRR) } \\
\text { Continuous aerobic } \\
\text { exercise } \\
40-50 \text { min }^{b}\end{array}$ & $\begin{array}{l}3 \text { sessions/week } \\
\text { Moderate intensity } \\
(60-70 \% \text { HRR) } \\
\text { Continuous aerobic } \\
\text { exercise } \\
50 \text { min }\end{array}$ & $\begin{array}{l}3 \text { sessions/week } \\
\text { Moderate-vigorous } \\
\text { intensity (70-75\% } \\
\text { HRR) } \\
\text { Continuous aerobic } \\
\text { exercise } \\
50 \text { min }\end{array}$ & $\begin{array}{l}3 \text { sessions/week } \\
\text { Vigorous intensity } \\
(75-80 \% \mathrm{HRR})^{\mathrm{a}} \\
\text { Continuous aerobic } \\
\text { exercise } \\
50 \mathrm{~min}\end{array}$ \\
\hline Resistance & $\begin{array}{l}3 \text { sessions/week } \\
\text { Low load (40-50\% } \\
1-\mathrm{RM})^{\mathrm{a}} \\
\text { Resistance training } \\
20-30 \text { min }^{b} \\
2 \times 12 \text { reps (6 } \\
\text { exercises) }\end{array}$ & $\begin{array}{l}3 \text { sessions/week } \\
\text { Low-moderate load } \\
(50-55 \% 1-R M)^{a} \\
\text { Resistance training } \\
30-40 \text { min }^{b} \\
3 \times 12 \text { reps ( } 6 \\
\text { exercises) }\end{array}$ & $\begin{array}{l}3 \text { sessions/week } \\
\text { Low-moderate load } \\
(55-60 \% 1-R M)^{a} \\
\text { Resistance training } \\
40-50 \text { min }^{b} \\
3-6 \times 12 \text { reps ( } 6 \\
\text { exercises) }\end{array}$ & $\begin{array}{l}3 \text { sessions/week } \\
\text { Moderate load } \\
(60-65 \% 1-R M)^{a} \\
\text { Resistance training } \\
50 \text { min; 3-6 × } 12 \\
\text { reps (6 exercises) }\end{array}$ & $\begin{array}{l}3 \text { sessions/week } \\
\text { Moderate-high load } \\
(70-75 \% 1-R M)^{a} \\
\text { Resistance training } \\
50 \text { min; } 3-6 \times 12 \\
\text { reps (6 exercises) }\end{array}$ & $\begin{array}{l}3 \text { sessions/week } \\
\text { High load }(75-80 \% \\
\text { 1-RM) } \\
\text { Resistance training } \\
50 \text { min; } 3-6 \times 12 \text { reps } \\
\text { (6 exercises) }\end{array}$ \\
\hline Combined & $\begin{array}{l}3 \text { sessions/week } \\
\text { Aerobic compo- } \\
\text { nent } \\
\text { Low intensity } \\
(40-50 \% \text { HRR) } \\
\text { Continuous aerobic } \\
\text { exercise } \\
\text { 10-15 min } \\
\text { Resistance compo- } \\
\text { nent } \\
\text { Low load (40-50\% } \\
\text { 1-RM) } \\
\text { Resistance training } \\
10-15 \text { min; } 2 \times 12 \\
\text { reps (3 exercises) }\end{array}$ & $\begin{array}{l}3 \text { sessions/week } \\
\text { Aerobic component } \\
\text { Low-moderate } \\
\text { intensity (50-55\% } \\
\text { HRR) } \\
\text { Continuous aerobic } \\
\text { exercise } \\
\text { 15-20 min } \\
\text { Resistance compo- } \\
\text { nent } \\
\text { Low-moderate load } \\
\text { (50-55\% 1-RM) }^{\mathrm{a}} \\
\text { Resistance training } \\
\text { 15-20 min; } 3 \times 12 \\
\text { reps (3 exercises) }\end{array}$ & $\begin{array}{l}3 \text { sessions/week } \\
\text { Aerobic compo- } \\
\text { nent } \\
\text { Low-moderate } \\
\text { Intensity (55-60\% } \\
\text { HRR) } \\
\text { Continuous aerobic } \\
\text { exercise } \\
\text { 20-25 min } \\
\text { Resistance compo- } \\
\text { nent } \\
\text { Low-moderate load } \\
\text { (60-70\% 1-RM) } \\
\text { Resistance training } \\
\text { 20-25 min; } 3-6 \times 12 \\
\text { reps (3 exercises) }\end{array}$ & $\begin{array}{l}3 \text { sessions/week } \\
\text { Aerobic compo- } \\
\text { nent } \\
\text { Moderate intensity } \\
(60-70 \% \text { HRR) } \\
\text { Continuous aerobic } \\
\text { exercise } \\
25 \text { min } \\
\text { Resistance com- } \\
\text { ponent } \\
\text { Moderate load } \\
\text { (65-70\% 1-RM) }^{\text {a }} \\
\text { Resistance training } \\
25 \text { min; 3-6 × 12 } \\
\text { reps (3 exercises) }\end{array}$ & $\begin{array}{l}3 \text { sessions/week } \\
\text { Aerobic compo- } \\
\text { nent } \\
\text { Moderate-vigorous } \\
\text { intensity (70-75\% } \\
\text { HRR) } \\
\text { Continuous aerobic } \\
\text { exercise } \\
25 \text { min } \\
\text { Resistance compo- } \\
\text { nent } \\
\text { Moderate-high load } \\
\text { (70-75\% 1-RM) } \\
\text { Resistance training } \\
25 \text { min; 3-6 × 12 } \\
\text { reps (3 exercises) }\end{array}$ & $\begin{array}{l}3 \text { sessions/week } \\
\text { Aerobic component } \\
\text { Vigorous intensity } \\
(75-80 \% \text { HRR) } \\
\text { Continuous aerobic } \\
\text { exercise } \\
25 \text { min } \\
\text { Resistance compo- } \\
\text { nent } \\
\text { High load (75-80\% } \\
\text { 1-RM) } \\
\text { Resistance training } \\
25 \text { min; } 3-6 \times 12 \text { reps } \\
(3 \text { exercises) }\end{array}$ \\
\hline
\end{tabular}

\footnotetext{
${ }^{a}$ Sessions will increase in intensity/load by $2.5-5 \%$ as tolerated between sessions during weeks 1-12 up to the max intensity/load for the fortnightly block, provided the duration (during weeks 1-6) remains the same for the sessions where intensity/load is changed

${ }^{b}$ Sessions will increase in duration by 5 min during weeks 1-6 up to the max time for that fortnightly block, provided the intensity/load remains the same for the session where duration is increased
} 
lower limb (barbell squat, goblet squat, deadlift, Romanian deadlift, lunge, lateral lunge) exercises included. In each session, participants will perform six exercises aimed at targeting all major muscle groups (Table 4). The participants will perform three different exercise regimes on a weekly basis, alternating every second week (Table 5). They will be monitored to track weights lifted and be provided with feedback on correct technique as needed. In weeks $1-2$, participants will perform $2 \times 12$ reps of the six exercises at $40-50 \% 1 \mathrm{RM}$ to allow them to become familiar with the different exercises. From weeks 3 to 4 , participants will perform $3 \times 12$ reps of each exercise at $50-55 \% 1 \mathrm{RM}$. From weeks 5 to 12, participants will perform up to six sets of each exercise to meet the prescribed time for each session (i.e. $50 \mathrm{~min}$ ). The load will progressively increase for all exercises performed from weeks $1-12$ from $40 \% 1 \mathrm{RM}$ in week one to $80 \%$ $1 \mathrm{RM}$ in week twelve (Table 3 ) once a participant can perform all sets of 12 reps with proper form in one session and/or once the participant reports finding the exercise easy. Each set of exercises will be followed by a 45 -s rest.

Combined This intervention will consist of $3 \times 50-\mathrm{min}$ sessions per week comprising of 25 min of progressive aerobic exercise (cross trainer, cycling) and $25 \mathrm{~min}$ (three exercises: one upper limb, one core, one lower limb) of a progressive resistance programme (Table 4). The resistance portion of this intervention can include any of the eighteen exercises outlined in the resistance intervention above. However, the prescription of compound exercises (bench press, squat etc.) will be prioritised each week over the inclusion of any single joint movements (i.e. triceps exercises). In line with the aerobic and resistance trial arms, both components (aerobic and resistance) of the combined intervention will increase in load/intensity across the 12 weeks from $40 \% 1 \mathrm{RM} / \mathrm{HRR}$ in week 1 to $80 \% 1 \mathrm{RM} / \mathrm{HRR}$ in week 12 (Table 3 ).

Control The control group will be instructed to maintain their physical activity levels for the 12-week intervention period. After this period, all participants randomised to the control group will be offered the opportunity to join one of the three exercise groups as per their preference to avail of an individualised and supervised exercise programme for 12 weeks.

\section{Sample size}

As this is a pilot study, which has the primary goal of evaluating the feasibility of the interventions and not ensuring there is adequate power to detect betweengroup differences, a formal sample size calculation is not required [48]. However, the researchers recognise that the sample size will need to be large enough to provide a degree of accuracy around the estimated effect of the interventions on a desired outcome (i.e. between-group difference in CRF which would be the primary outcome in an RCT) which would indicate whether a definitive $\mathrm{RCT}$ is worth pursuing. We estimated that we would need to recruit approximately $10 \%$ of the number of participants needed for a full-scale RCT. Based on previous research in this area [67], a sample size calculation for a definitive RCT indicates that we would need to recruit 484 participants. Therefore, allowing for $20 \%$ attrition, we aim to recruit 60 participants for this pilot study to inform the power analysis for a full-scale RCT.

\section{Blinding}

Blinding of participants to their group allocation will not be possible due to the nature of the interventions. However, all participants will be informed (information leaflet) that they have an equal chance of being randomly allocated to any one of the four groups. Once the intervention commences, blinding of the assessors and instructors will not be possible. However, the assessor and exercise instructors will not be involved in group allocation and will remain unaware of the unique participant numbers until completion of the data analysis. The trial statistician will also be unaware of group allocation until completion of data analysis.

\section{Statistical methods}

To evaluate the feasibility of the intervention, the number of eligible participants recruited, randomised and retained as well as dropouts lost to follow-up will be analysed as percentages. Data on participants attendance adherence to and compliance with prescribed interventions (i.e. average adherence to reps, sets, HR) will be analysed and the mean results reported as percentages. The incidence of adverse events (an adverse event defined as an event which a participant identifies a problem caused by the exercise programme that required the participant to seek treatment from a health professional and/or prevents participation in the programme) will also be analysed as percentages across all interventions. The acceptability of trial procedures based on participants' experiences will be explored qualitatively as outlined in this protocol below. Feasibility data will be used to inform the development of a potential full-scale RCT.

In line with CONSORT guidance, the analysis of secondary outcomes will be conducted on an intention to treat basis. All data collected from participants (sociodemographic information, outcome questionnaire scores etc.) will be coded, cleaned and checked for errors. The data will then be entered into the Statistical Package for the Social Sciences (SPSS Version 26) for analysis. The 
Table 4 Resistance exercises included in the resistance and combined programmes

\begin{tabular}{|c|c|}
\hline Exercise & Variations \\
\hline \multicolumn{2}{|l|}{ Upper body } \\
\hline Bench press ${ }^{a}$ & $\begin{array}{l}\text { Standard flat bench press with BB/DB } \\
\text { Incline bench press with BB/DB } \\
\text { Grip: wide, normal, narrow }\end{array}$ \\
\hline Shoulder press & $\begin{array}{l}\text { Overhead press with DB } \\
\text { BB press } \\
\text { Grip: wide, narrow } \\
\text { Position: standing, seated }\end{array}$ \\
\hline Bent over row & $\begin{array}{l}\text { Standard BB row } \\
\text { Single arm supported row with } \mathrm{DB} / \mathrm{KB}\end{array}$ \\
\hline Raise & $\begin{array}{l}\text { Forward raise } \\
\text { Lateral raise } \\
\text { Bent over fly } \\
\text { Resistance: } D B \text {, weight plate }\end{array}$ \\
\hline Bicep exercises & $\begin{array}{l}\text { Curl with DB } \\
\text { Curl with BB } \\
\text { Position: standing, seated } \\
\text { Grip: Supine, 'hammer', alternating supine and prone ('Zottman' curl) }\end{array}$ \\
\hline Triceps exercises & $\begin{array}{l}\text { Standing/seated behind the head extensions without resistance or 2xDB } \\
\text { Lying triceps extensions } \\
\text { French press with DB/KB } \\
\text { Bench dips (BW or weight plate) } \\
\text { KB/DB halos }\end{array}$ \\
\hline Kettlebell swings & $\begin{array}{l}\text { Two-hand 'Russian'swing } \\
\text { Alternating swing } \\
\text { Single hand swing } \\
\text { Overhead 'American'swing }\end{array}$ \\
\hline \multicolumn{2}{|l|}{ Core } \\
\hline Push-ups & $\begin{array}{l}\text { Wall push-up } \\
\text { Elevated push-up on bench } \\
\text { Push up on knees } \\
\text { Push up on KB } \\
\text { Standard push-up } \\
\text { Position: wide hand position, narrow hand position }\end{array}$ \\
\hline Seated twist & $\begin{array}{l}\text { Sitting with legs supported BW } \\
\text { Sitting with legs supported with medicine ball/ KB } \\
\text { Sitting with legs lifted off ground and crossed BW } \\
\text { Sitting with legs lifted off ground and crossed with medicine ball/ KB) } \\
\text { Sitting with legs lifted off ground and held together (BW, with medicine ball/ KB)) } \\
\text { Position: variance in torso lean back }\end{array}$ \\
\hline Overhead medicine ball slam & $\begin{array}{l}\text { Position: depth of squat } \\
\text { Resistance: weight of medicine ball }\end{array}$ \\
\hline Hip bridge & $\begin{array}{l}\text { Two-legged bridge BW } \\
\text { Two-legged bridge with resistance (DB, weight plate or bar) } \\
\text { Single leg bridge with heel support of other foot } \\
\text { Single leg bridge }\end{array}$ \\
\hline 4-point kneel (swimming exercise) & $\begin{array}{l}\text { Slide one leg back along mat with/ without leg lift } \\
\text { Opposite hand opposite leg (with hand still in contact with mat) } \\
\text { Opposite hand opposite leg lift } \\
\text { With weight plate in hand } \\
\text { Pull-through with KB/DB/weight plate }\end{array}$ \\
\hline Opposite leg touch (standing twist) & $\begin{array}{l}\text { Twist to touch opposite knee up } \\
\text { Twist to touch opposite leg kicked out } \\
\text { Twist with weight plate in hand }\end{array}$ \\
\hline \multicolumn{2}{|l|}{ Lower body } \\
\hline Squat $^{\mathrm{a}}$ & $\begin{array}{l}\text { Chair/bench squat (BW, with KB/DB, with BB) } \\
\text { DB/KB'Goblet'squat } \\
\text { BB Back squat } \\
\text { BB Front Squat } \\
\text { Split squat (one foot behind on floor; one foot supported on bench) } \\
\text { Foot position: hip width, sumo (wide) }\end{array}$ \\
\hline
\end{tabular}


Table 4 (continued)

\begin{tabular}{ll}
\hline Exercise & Variations \\
\hline Lunges & Forward/reverse/side lunge \\
& Resistance: BW, Single DB/KB held in front; double DB/KB racked at shoulder or \\
& held down by sides; BB on back \\
Deadlift & Position: stationary, walking lunge \\
& Standard BB deadlift \\
Kettlebell swings & Sumo deadlift \\
& Romanian deadlift with DB or BB \\
& Two-hand 'Russian'swing \\
& Alternating swing \\
& Single hand swing \\
& Overhead'American'swing \\
\hline
\end{tabular}

$B B$ barbell, $B W$ body weight, $D B$ dumbbell, $K B$ kettlebell

${ }^{\text {a }}$ All participants in resistance or combined programme will squat/bench or progress to squat/bench with BB unless limited physically (i.e. by injury etc.). Variations with $\mathrm{KB} / \mathrm{DB}$ will be used during consecutive sessions for bench/squat

study's statistician (C.B) will remain blinded to group allocation until the analysis is complete. The change in mean values before and after intervention will be calculated for secondary outcomes. Analysis of variance (ANOVA) and $t$-tests will be applied to compare between-group and within group-differences at baseline and follow-up for each outcome. If there are sufficient participants $(n=60)$, the data will be analysed using analysis of covariance (ANCOVA) with the age and BMI as covariates. Statistical significance will be defined as $p$ $\leq 0.05$.

\section{Follow-up assessment}

During the last week of the 12-week intervention period, all participants will be approached by the trial coordinator to arrange an appointment for a follow-up assessment within seven days post-intervention. Similar to the baseline assessment, participants will be instructed to attend ISH on a separate day after the intervention has ended to have their follow-up assessment following the procedures

Table 5 Sample exercise plan

\begin{tabular}{lll}
\hline Week'A' & & \\
Session 1 & Session 2 & Session 3 \\
Bench press with BB & Shoulder press & Biceps exercises \\
Bent over row & Raise/KB swing & Triceps exercises \\
Seated twist & Push-up & Standing twist \\
Overhead ball slam & Hip bridge & 4-point kneel \\
Squat with KB/DB & Squat with BB & Deadlift with BB \\
Side lunge & Romanian deadlift & Lunge \\
Week'B' & & \\
Session 1 & & \\
Shoulder press & Session 2 & Session 3 \\
Biceps exercises & Bench with BB & Bent over row \\
Push-up & Raise/KB swing & Triceps exercises \\
Seated twist & 4-point kneel & Standing twist \\
Squat with BB & Hip bridge & Overhead ball slam \\
Romanian deadlift & Squat with DB/KB & Deadlift with BB \\
& Lunge & Side lunge \\
\hline
\end{tabular}

detailed above. The participants will also be issued the combined set of valid and reliable self-reported outcome questionnaires used pre-intervention.

\section{Qualitative study}

All participants randomised to the exercise interventions will be provided an exit questionnaire and invited to participate in a semi-structured telephone interview (or face-to-face interview if preferred/convenient) within two weeks of completing their follow-up assessment. The exit questionnaire was internally developed specifically for this study and will explore participants perception of the intervention including topics such as the randomisation process, intervention design (i.e. number of sessions etc.) and satisfaction with the intervention. We aim to conduct a minimum of 18 (6 per exercise group) semi-structured interviews. Interviews will take approximately 30-40 min. Participants who consent to take part in an interview will either be contacted by phone at their convenience or invited to attend ISH for a face-to-face interview and will discuss a predetermined set of topics. These topics will be guided by the theoretical framework of acceptability (TFA) domains [68] and will include reasons for participation in the trial, their understanding and the acceptability of the trial procedures, their experiences and feelings around the exercise programmes, their expectations and satisfaction with the programmes, the barriers/motivators to participation in the trial/exercise in general, self-efficacy, changes to lifestyle, behaviours, beliefs or feelings following participation in the trial and the likelihood of continuing participation in exercise. The interview sessions will be audio-recorded and then transcribed verbatim for analysis of themes. 


\section{Data analysis}

In line with Braun and Clarke's method for thematic analysis [69], qualitative data collected from semi-structured interviews and exit questionnaires will be coded and analysed. Themes and sub-themes will be identified by two members of the research team. To ensure reliability of themes, an independent investigator not otherwise involved in the study will review a sub-set of the transcripts (10\%) and consensus reached. Questions included in the exit questionnaire which utilises a Likert scale will be scored and the overall percentage of participants who selected specific statements will be reported.

\section{Results}

Participant flow through the study is detailed in Fig. 1. Recruitment of participants will begin in August 2021 and is expected to last until December 2022. Data analyses are expected to begin in early 2023.

\section{Discussion}

We have presented the rationale and design of a pilot randomised controlled trial which will investigate and evaluate the effectiveness of different training modalities (aerobic, resistance and combined) in women living with obesity compared to a non-exercise control. The results of this study will help inform exercise prescription for women living with obesity and will be presented as soon as they are available.

\begin{abstract}
Abbreviations
5RM: Five repetition maximum; \%BF: Percentage body fat; ANOVA: Analysis of variance; ANCOVA: Analysis of covariance; BMI: Body mass index; CONSORT: Consolidated Standards of Reporting Trials; CRF: Cardiorespiratory fitness; F.I.T.T.: Frequency, intensity, time and type; FFM: Fat-free mass; FM: Fat mass; HR: Heart rate; ICPO: Irish Coalition for People Living with Obesity; ISH: Institute for Sport and Health; LM: Lean mass; PAR-Q+: Physical Activity Readiness Questionnaire for Everyone; RCT: Randomised controlled trial; RPE: Rating of perceived exertion; SPIRIT: Standard Protocol Items: Recommendations for Interventional Trials; SPSS: Statistical Package for the Social Sciences; TFA: Theoretical framework of acceptability; UCD: University College Dublin; $\mathrm{VO}_{2}$ : Oxygen uptake; $\mathrm{VO}_{2}$ max: Maximal oxygen uptake; WHR: Waist-hip ratio; WC: Waist circumference.
\end{abstract}

\section{Acknowledgements}

Not Applicable.

\section{Confidentiality}

The PI is the custodian of the research data and will take responsibility for its management, including security, storage and retention. S/he will ensure that the research participants are informed of his/her research team's obligations in relation to the data. The study information leaflet and consent form will provide a description of the steps that will be taken to protect the privacy of the participant and indicate under what circumstances records will be made available and to whom, including future use of data and data sharing, as applicable to this research project (e.g., anonymised data sharing on data repositories such as Zenodo and the Irish Social Science Data Archive (ISSDA)). Only the research team named in this funding application will have access to the research data, and strict protocols to access all physical and electronic locations where data are stored will be put in place. Data will only be processed with written prior consent. All data will be anonymised using the following techniques: removal of direct identifiers (names, addresses, telephone numbers, emails etc.), category aggregation to reduce precision (band ages etc.), use of standard coding frames (e.g., EX01A, EX: exercise, 01: subject number, A: aerobic), generalised meaning of detailed text and documentation detailing changes made. Data will be retained for 5 years after the completion of the research project. Once these 5 years have expired, the data will be disposed of and/or deleted securely and confidentially in a manner appropriate to its format, and in line with UCD's policies.

\section{Dissemination}

Articles reporting the findings of this study will be submitted for publication to scientific journals, will be presented at relevant conferences and disseminated with professionals involved in obesity prevention.

\section{Authors' contributions}

MED, GO'D, CB, CC and BC all made substantial contributions to the conception or design of the work, to drafting the work or revising it critically for important intellectual content and have approved the final submitted version to be published. All authors have agreed both to be personally accountable for the author's own contributions and to ensure that questions related to the accuracy or integrity of any part of the work, even ones in which the author was not personally involved, are appropriately investigated, resolved, and the resolution documented in the literature.

\section{Funding}

This work was supported by University College Dublin [grant number: N/A].

\section{Availability of data and materials}

Data of relevance to the reported findings are included in the main body of the paper with additional data provided as supplementary information. Datasets generated and/or analysed during this study will be made available in an online repository following the conclusion of the study. During the course of the study, all electronic data will be stored on the institution's encrypted drive and on an institution's encrypted computer. Along with the hard copies of the data, this computer will be stored in a locked filing cabinet in a locked office in the institution which only the research team have access to.

\section{Declarations}

Ethics approval and consent to participate

This study has obtained full ethical approval from the human research ethics committee of the host institution (University College Dublin) [Ethics Number: LS-21-59-Davis-ODonoghue]. All participants will provide written informed consent to participate (obtained by the trial coordinator).

\section{Consent for publication}

All participant data will be anonymised. Participants will provide written consent in the consent form for this data to be published.

\section{Competing interests}

There are no competing interests for any author.

\section{Author details}

${ }^{1}$ Department: School of Public Health, Physiotherapy and Sports Science, University College Dublin, Dublin 4, Ireland D04 V1W8. ${ }^{2}$ Department of Physical Education and Sport Sciences, University of Limerick, Limerick, Ireland.

Received: 18 November 2021 Accepted: 9 February 2022

Published online: 21 February 2022

\section{References}

1. GBD 2017 Risk Factor Collaborators. Global, regional, and national comparative risk assessment of 84 behavioural, environmental and occupational, and metabolic risks or clusters of risks for 195 countries and territories, 1990-2017: a systematic analysis for the Global Burden of Disease Study 2017. Lancet (London, England). 2018;392(10159):1923. DOl:https://doi.org/10.1016/S0140-6736(18)32225-6 
2. Seidell JC, Halberstadt J. The global burden of obesity and the challenges of prevention. Ann Nutr Metab. 2015;66(Suppl. 2):7-12. https://doi.org/ $10.1159 / 000375143$

3. NCD Risk Factor Collaboration. Trends in adult body-mass index in 200 countries from 1975 to 2014: a pooled analysis of 1698 populationbased measurement studies with 19.2 million participants. Lancet. 2016;387(10026):1377-96. https://doi.org/10.1016/S0140-6736(16) 30054-X.

4. Hutchesson MJ, Houwer MD, Brown HM, Lim S, Moran LJ, Vincze L, et al. Supporting women of childbearing age in the prevention and treatment of overweight and obesity: a scoping review of randomized control trials of behavioral interventions. BMC Womens Health. 2020;20(1):14. https:// doi.org/10.1186/s12905-020-0882-3.

5. Wane S, Van Uffelen JG, Brown W. Determinants of weight gain in young women: a review of the literature. J Womens Health. 2010;19(7):1327-40. https://doi.org/10.1089/jwh.2009.1738

6. Berg C, Rosengren A, Aires N, Lappas G, Toren K, Thelle D, et al. Trends in overweight and obesity from 1985 to 2002 in Göteborg. West Sweden. Int J Obes. 2005;29(8):916-24. https://doi.org/10.1038/sj.ijo.0802964.

7. Adamson L, Brown W, Byles J, Chojenta C, Dobson A, Fitzgerald D, et al. Women's weight: findings from the Australian Longitudinal Study on Women's Health. Canberra: Australian Government Department of Health and Ageing. Canberra, ACT Australia; 2007.

8. Drøyvold WB, Nilsen TI, Krüger $\varnothing$, Holmen TL, Krokstad S, Midthjell K, et al. Change in height, weight and body mass index: longitudinal data from the HUNT Study in Norway. Int J Obes. 2006;30(6):935-9. https://doi.org/ 10.1038/sj.ijo.0803178.

9. Ogden CL. Mean body weight, height, and body mass index: United States 1960-2002. Centers for Disease Control and Prevention, National Center for Health Statistics: Department of Health and Human Services; 2004.

10. Haftenberger M, Mensink GB, Herzog B, Kluttig A, Greiser KH, Merz B, et al. Changes in body weight and obesity status in German adults: results of seven population-based prospective studies. Eur J Clin Nutr. 2016;70(3):300-5. https://doi.org/10.1038/ejcn.2015.179.

11. Lumsden MA, Hor K. Impact of obesity on the health of women in midlife. Obstetr Gynaecol. 2015;17(3):201-8. https://doi.org/10.1111/tog.12199.

12. Ansari S, Haboubi $\mathrm{H}$, Haboubi N. Adult obesity complications: challenges and clinical impact. Ther Adv Endocrinol Metab. 2020;1 1:2042018820934955. https://doi.org/10.1177/2042018820934955.

13. Censin JC, Peters SA, Bovijn J, Ferreira T, Pulit SL, Mägi R, et al. Causal relationships between obesity and the leading causes of death in women and men. PLoS genetics. 2019;15(10):e1008405. https://doi.org/10.1371/ journal.pgen.1008405.

14. Katz A. CE: Obesity-Related Cancer in Women: A Clinical Review. Am J Nurs. 2019;119(8):34-40. https://doi.org/10.1097/01.NAJ.0000577332. 56265.51 .

15. Kulie T, Slattengren A, Redmer J, Counts H, Eglash A, Schrager S. Obesity and women's health: an evidence-based review. J Am Board Fam Med. 2011;24(1):75-85. https://doi.org/10.3122/jabfm.2011.01.100076.

16. Pan A, Kawachi I, Luo N, Manson JE, Willett WC, Hu FB, et al. Changes in body weight and health-related quality of life: 2 cohorts of US women. Am J Epidemiol. 2014;180(3):254-62. https://doi.org/10.1093/aje/kwu136.

17. Sun Q, Townsend MK, Okereke Ol, Franco OH, Hu FB, Grodstein F. Adiposity and weight change in mid-life in relation to healthy survival after age 70 in women: prospective cohort study. Bmj. 2009;339. https://doi.org/10. 1136/bmj.b3796.

18. Zheng Y, Manson JE, Yuan C, Liang MH, Grodstein F, Stampfer MJ, et al. Associations of weight gain from early to middle adulthood with major health outcomes later in life. Jama. 2017;318(3):255-69. https://doi.org/ 10.1001/jamanetworkopen.2019.17371.

19. Ortega FB, Ruiz JR, Labayen I, Lavie CJ, Blair SN. The Fat but Fit paradox: what we know and don't know about it. Br J Sports Med. 2018;52(3):1513. https://doi.org/10.1136/bjsports-2016-097400.

20. McAuley PA, Beavers KM. Contribution of cardiorespiratory fitness to the obesity paradox. Progress Cardiovasc Dis. 2014;56(4):434-40. https://doi. org/10.1016/j.pcad.2013.09.006.

21. Kodama S, Saito K, Tanaka S, Maki M, Yachi Y, Asumi M, et al. Cardiorespiratory fitness as a quantitative predictor of all-cause mortality and cardiovascular events in healthy men and women: a meta-analysis. Jama. 2009;301(19):2024-35. https://doi.org/10.1001/jama.2009.681.
22. Carnethon MR, Gulati M, Greenland P. Prevalence and cardiovascular disease correlates of low cardiorespiratory fitness in adolescents and adults. Jama. 2005;294(23):2981-8. https://doi.org/10.1001/jama.294.23.2981.

23. Blair SN, Kohl HW, Paffenbarger RS, Clark DG, Cooper KH, Gibbons LW. Physical fitness and all-cause mortality: a prospective study of healthy men and women. Jama. 1989;262(17):2395-401. https://doi.org/10.1001/ jama.262.17.2395.

24. Busutil R, Espallardo O, Torres A, Martínez-Galdeano L, Zozaya N, HidalgoVega A. The impact of obesity on health-related quality of life in Spain. Health Qual life Outcomes. 2017;15(1):1-1. https://doi.org/10.1186/ s12955-017-0773-y.

25. Forhan M, Gill SV. Obesity, functional mobility and quality of life. Best Pract Res Clin Endocrinol Metab. 2013;27(2):129-37. https://doi.org/10. 1016/j.beem.2013.01.003.

26. Department of Health. Healthy Ireland Summary Report 2019. Dublin: Department of Health; 2019. https://assets.gov.ie/41141/e5d6fea3a5 9a4720b081893e11fe299e.pdf

27. Blackwell DL, Clarke TC. State variation in meeting the 2008 federal guidelines for both aerobic and muscle-strengthening activities through leisure-time physical activity among adults aged 18-64: United States, 2010-2015. National Health Stat Rep. 2018;1 (112):1-22.

28. Australian Institute of Health and Welfare. Insufficient physical activity. Cat. no. PHE 248. Canberra: AlHW; 2020. https://www.aihw.gov.au/repor ts/risk-factors/insufficient-physical-activity/contents/insufficient-physicalactivity

29. Guthold R, Stevens GA, Riley LM, Bull FC. Worldwide trends in insufficient physical activity from 2001 to 2016: a pooled analysis of 358 populationbased surveys with 1.9 million participants. Lancet Global Health. 2018;6(10):e1077-86. https://doi.org/10.1016/S2214-109X(18)30357-7.

30. U.S. Department of Health and Human Services. Physical Activity Guidelines for Americans. 2nd ed. Washington, DC: U.S. Department of Health and Human Services; 2018.

31. Caspersen CJ, Pereira MA, Curran KM. Changes in physical activity patterns in the United States, by sex and cross-sectional age. Med Sci Sports Exer. 2000;32(9):1601-9. https://doi.org/10.1097/00005768-20000 9000-00013.

32. Butler SM, Black DR, Blue CL, Gretebeck RJ. Change in diet, physical activity, and body weight in female college freshman. Am J Health Behav. 2004;28(1):24-32. https://doi.org/10.5993/ajhb.28.1.3.

33. Jung ME, Bray SR, Ginis KA. Behavior change and the freshman 15: tracking physical activity and dietary patterns in 1st-year university women. J Am College Health. 2008;56(5):523-30. https://doi.org/10.3200/JACH. 56.5.523-530.

34. Sheel AW, Dominelli PB, Molgat-Seon Y. Revisiting dysanapsis: sex-based differences in airways and the mechanics of breathing during exercise. Exp Physiol. 2016;101(2):213-8. https://doi.org/10.1113/EP085366.

35. Al-Mallah MH, Juraschek SP, Whelton S, Dardari ZA, Ehrman JK, Michos $E D$, et al. Sex Differences in cardiorespiratory fitness and all-cause mortality: the Henry Ford Exerclse Testing (FIT) project. Mayo Clin Proc. 2016;91(6):755-62. https://doi.org/10.1016/j.mayocp.2016.04.002.

36. Devries MC. Sex-based differences in endurance exercise muscle metabolism: impact on exercise and nutritional strategies to optimize health and performance in women. Exp Physiol. 2016;101(2):243-9. https://doi. org/10.1113/EP085369.

37. Zeiher J, Ombrellaro KJ, Perumal N, Keil T, Mensink GB, Finger JD. Correlates and determinants of cardiorespiratory fitness in adults: a systematic review. Sports Med Open. 2019;5(1):1-24. https://doi.org/10.1186/ s40798-019-0211-2.

38. Wang CY, Haskell WL, Farrell SW, LaMonte MJ, Blair SN, Curtin LR, et al. Cardiorespiratory fitness levels among US adults 20-49 years of age: findings from the 1999-2004 National Health and Nutrition Examination Survey. Am J Epidemiol. 2010;171(4):426-35. https://doi.org/10.1093/aje/kwp412.

39. Loe H, Rognmo $\varnothing$, Saltin B, Wisløff U. Aerobic capacity reference data in 3816 healthy men and women 20-90 years. PloS one. 2013;8(5):e64319. https://doi.org/10.1371/journal.pone.0064319.

40. Diaz-Canestro C, Montero D. Sex dimorphism of VO2max trainability: a systematic review and meta-analysis. Sports Med. 2019;49(12):1949-56. https://doi.org/10.1007/s40279-019-01180-z.

41. Ansdell P, Thomas K, Hicks KM, Hunter SK, Howatson G, Goodall S. Physiological sex differences affect the integrative response to exercise: acute 
and chronic implications. Exp Physiol. 2020;105(12):2007-21. https://doi. org/10.1113/EP088548.

42. Irving BA, Davis CK, Brock DW, et al. Effect of exercise training intensity on abdominal visceral fat and body composition. Med Sci Sports Exerc. 2008;40(11):1863-72. https://doi.org/10.1249/MSS.0b013e3181801d40.

43. Irwin ML, Yasui Y, Ulrich CM, et al. Effect of exercise on total and intra-abdominal body fat in postmenopausal women: a randomized controlled trial. JAMA. 2003;289(3):323-30. https://doi.org/10.1001/jama. 289.3.323.

44. Mohanka M, Irwin M, Heckbert SR, et al. Serum lipoproteins in overweight/obese postmenopausal women: a one-year exercise trial. Med Sci Sports Exerc. 2006;38(2):231-9. https://doi.org/10.1249/01.mss.00001 84584.95000.e4.

45. Castro EA, Peinado AB, Benito PJ, Galindo M, González-Gross M, Cupeiro R. PRONAF Study Group. What is the most effective exercise protocol to improve cardiovascular fitness in overweight and obese subjects? I Sport Health Sci. 2017;6(4):454-61. https://doi.org/10.1016/j.jshs.2016.04.007.

46. O'Donoghue G, Blake C, Cunningham C, Lennon O, Perrotta C. What exercise prescription is optimal to improve body composition and cardiorespiratory fitness in adults living with obesity? A network meta-analysis. Obes Rev. 2020. https://doi.org/10.1111/obr.13137.

47. Willis LH, Slentz CA, Bateman LA, Shields AT, Piner LW, Bales CW, et al. Effects of aerobic and/or resistance training on body mass and fat mass in overweight or obese adults. J Appl Physiol. 2012. https://doi.org/10. 1152/japplphysiol.01370.2011.

48. Eldridge SM, Chan CL, Campbell MJ, Bond CM, Hopewell S, Thabane L, et al. CONSORT 2010 statement: extension to randomised pilot and feasibility trials. BMJ. 2016;355:5239. https://doi.org/10.1136/bmj.i5239.

49. Chan A-W, Tetzlaff JM, Altman DG, Laupacis A, Gøtzsche PC, Krleža-Jerić K, et al. SPIRIT 2013 Statement: Defining standard protocol items for clinical trials. Ann Intern Med. 2013;158:200-7. https://doi.org/10.7326/00034819-158-3-201302050-00583

50. Williams B, Mancia G, Spiering W, Agabiti Rosei E, Azizi M, Burnier M, et al. 2018 ESC/ESH Guidelines for the management of arterial hypertension: The Task Force for the management of arterial hypertension of the European Society of Cardiology (ESC) and the European Society of Hypertension (ESH). Eur Heart J. 2018;39(33):3021-104.

51. American College of Sports Medicine. ACSM's guidelines for exercise testing and prescription. 9th ed: Lippincott Williams \& Wilkins; 2014.

52. Ma WY, Yang CY, Shih SR, Hsieh HJ, Hung CS, Chiu FC, et al. Measurement of waist circumference: midabdominal or iliac crest? Diabetes Care. 2013;36(6):1660-6.

53. Mathiowetz V, Rennells C, Donahoe L. Effect of elbow position on grip and key pinch strength. J Hand Surg. 1985;10(5):694-7.

54. World Health Organisation. Obesity: preventing and managing the global epidemic. World Health Organ Techn Rep Series. 2000;894:1-253.

55. Pollock ML, Foster C, Schmidt D, Hellman C, Linnerud AC, Ward A. Comparative analysis of physiologic responses to three different maximal graded exercise test protocols in healthy women. Am Heart J. 1982;103(3):363-73. https://doi.org/10.1016/0002-8703(82)90275-7.

56. Balke B, Ware RW. An experimental study of physical fitness of Air Force personnel. U.S. Armed Forces Med J. 1959;10:675.

57. Knaier R, Niemeyer M, Wagner J, Infanger D, Hinrichs T, Klenk $C$, et al. Which cutoffs for secondary $\mathrm{V} O 2 \mathrm{max}$ criteria are robust to diurnal variations? Med Sci Sports Exerc. 2019;51(5):1006-13. https://doi.org/10.1249/ MSS.0000000000001869.

58. Bjørke AC, Raastad T, Berntsen S. Criteria for the determination of maximal oxygen uptake in patients newly diagnosed with cancer: baseline data from the randomized controlled trial of physical training and cancer (Phys-Can). Plos One. 2020;15(6):e0234507. https://doi.org/10.1371/journ al.pone.0234507.

59. Eike GS, Aadland E, Blom EE, Riiser A. Validation of a modified submaximal balke protocol to assess cardiorespiratory fitness in individuals at high risk of or with chronic health conditions-a pilot study. Front Sports Active Living. 2021;22(3):72. https://doi.org/10.3389/fspor.2021.642538.

60. Coquart JB, Garcin M, Parfitt G, Tourny-Chollet C, Eston RG. Prediction of maximal or peak oxygen uptake from ratings of perceived exertion. Sports Med. 2014;44(5):563-78. https://doi.org/10.1007/ s40279-013-0139-5.

61. Kokkinos P, Kaminsky LA, Arena R, Zhang J, Myers J. New generalized equation for predicting maximal oxygen uptake (from the Fitness
Registry and the Importance of Exercise National Database). Am J Cardiol. 2017;120(4):688-92.

62. Williams N. The Borg rating of perceived exertion (RPE) scale. Occupational Med. 2017;67(5):404-5. https://doi.org/10.1093/occmed/kqx063.

63. Mackenzie RM, Ells LJ, Simpson SA, Logue J. Core outcome set for behavioural weight management interventions for adults with overweight and obesity: standardised reporting of lifestyle weight management interventions to aid evaluation (STAR-LITE). Obesity Reviews. 2020;21(2):e12961. https://doi.org/10.1111/obr.12961.

64. Alligier M, Barrès R, Blaak EE, Boirie Y, Bouwman J, Brunault P, et al. OBEDIS core variables project: European expert guidelines on a minimal core set of variables to include in randomized, controlled clinical trials of obesity interventions. Obesity Facts. 2020;13(1):1-28. https://doi.org/10.1159/ 000505342.

65. Zdziarski LA, Wasser JG, Vincent HK. Chronic pain management in the obese patient: a focused review of key challenges and potential exercise solutions. J Pain Res. 2015;8:63. https://doi.org/10.2147/JPR.S55360.

66. Okifuji A, Hare BD. The association between chronic pain and obesity. J Pain Res. 2015;8:399. https://doi.org/10.2147/JPR.S55598.

67. Sarsan A, Ardiç F, Özgen M, Topuz O, Sermez Y. The effects of aerobic and resistance exercises in obese women. Clin Rehabil. 2006;20(9):773-82. https://doi.org/10.1177/0269215506070795

68. Sekhon M, Cartwright M, Francis JJ. Acceptability of healthcare interventions: an overview of reviews and development of a theoretical framework. BMC Health Serv Res. 2017;17(1):1-3. https://doi.org/10.1186/ s12913-017-2031-8.

69. Braun V, Clarke V. Chapter 2: Thematic analysis. In: Cooper HE, Camic PM, Long DL, Panter AT, Rindskopf DE, Sher KJ, editors. APA handbook of research methods in psychology, Vol 2: Research designs: quantitative, qualitative, neuropsychological, and biological; 2012. https://doi.org/10. 1037/13620-00.

\section{Publisher's Note}

Springer Nature remains neutral with regard to jurisdictional claims in published maps and institutional affiliations.

Ready to submit your research? Choose BMC and benefit from:

- fast, convenient online submission

- thorough peer review by experienced researchers in your field

- rapid publication on acceptance

- support for research data, including large and complex data types

- gold Open Access which fosters wider collaboration and increased citations

- maximum visibility for your research: over $100 \mathrm{M}$ website views per year

At BMC, research is always in progress.

Learn more biomedcentral.com/submissions 